BULLETIN Bulletin hispanique

HispaniQuE Université Michel de Montaigne Bordeaux

114-1 | 2012

Varia

\title{
Alexis Grohman y Maarten Steenmeijer (eds.), Allí donde uno diría que ya no puede haber nada. Tu rostro mañana de Javier Marías
}

Rodopi, Amsterdam - New York, 2009

Geneviève Champeau

\section{OpenEdition}

\section{Journals}

Edición electrónica

URL: http://journals.openedition.org/bulletinhispanique/1970

DOI: 10.4000/bulletinhispanique. 1970

ISSN: 1775-3821

Editor

Presses universitaires de Bordeaux

Edición impresa

Fecha de publicación: 1 junio 2012

Paginación: 495-497

ISBN: 978-2-86781-812-7

ISSN: 0007-4640

\section{Referencia electrónica}

Geneviève Champeau, « Alexis Grohman y Maarten Steenmeijer (eds.), Allí donde uno diría que ya no puede haber nada. Tu rostro mañana de Javier Marías », Bulletin hispanique [En línea], 114-1 | 2012, Publicado el 27 mayo 2013, consultado el 23 septiembre 2020. URL : http://journals.openedition.org/ bulletinhispanique/1970; DOI : https://doi.org/10.4000/bulletinhispanique.1970

Este documento fue generado automáticamente el 23 septiembre 2020

Tous droits réservés 


\title{
Alexis Grohman y Maarten Steenmeijer (eds.), Alli donde uno diría que ya no puede haber nada. Tu rostro mañana de Javier Marías
}

\author{
Rodopi, Amsterdam - New York, 2009
}

\section{Geneviève Champeau}

\section{REFERENCIA}

Alexis Grohman y Maarten Steenmeijer (eds.), Allí donde uno diría que ya no puede haber nada. Tu rostro mañana de Javier Marías, Rodopi. - Amsterdam - New York, 2009, 369 p.

1 Las contribuciones reunidas en este libro erigen un monumento a la novela de Javier Marías, Tu rostro mañana -tres tomos respectivamente subtitulados Fiebre y lanza (2001), Baile y sueño (2004), Veneno y sombra y adiós (2007), reeditados en un solo volumen en 2009- y al mismo escritor, una de las figuras más destacadas de la prosa española contemporánea. Los estudios reunidos hacen de esta ambiciosa obra narrativa de casi 1600 páginas en su versión original una atalaya desde la cual entender mejor no sólo la novela objeto del volumen sino la maduración de la empresa literaria que a ella conduce.

El libro que editan Alexis Grohman y Maarten Steenmeijer se adentra por etapas en el universo del escritor, en sucesivas calas no exentas de ecos y variaciones, principios de composición tan propios de Javier Marías que contribuyen a la cohesión del volumen.

Después de un breve prólogo que recalca la coherencia, la excelencia y la idiosincrasia literaria de Javier Marías, se reproducen, a modo de «Prolegómenos», junto con la respuesta de Francisco Rico, el discurso de ingreso del novelista en la Real Academia Española, «Sobre la dificultad de contar», una reflexión sobre uno de los fundamentos 
de su poética, la imposibilidad de una narración fiel y total en la que se origina una de las paradojas de la ficción condenada a «contar lo que nunca ha sucedido».

4 La segunda sección dedicada a «Primeras lecturas» inicia la tarea interpretativa exponiendo, en textos breves y sugestivos, lo que cinco destacados lectores estiman ser las dominantes de esta novela en tres entregas: la ambición totalizadora de una escritura que aúna narrar y pensar, preocupaciones cognitivas, éticas y estéticas (Jordi Gracia, Domingo Ródenas de Moya); la obsesión por un tiempo destructor y la consiguiente elaboración de una poética que dilata el instante (Edmundo Paz Soldán) y «estanca [...] el tiempo en albercas verbales» (César Pérez García); la conciliación de la máxima exigencia literaria con arquetipos de la literatura popular (Félix de Azúa); en fin, el arte de la variación y una concepción musical de la composición (César Pérez García).

5 A continuación, la sección «Estudios» desarrolla los precedentes temas a los que suma otros nuevos. Los catorce artículos en ella reunidos abarcan diferentes líneas semánticas que se van entrelazando en la obra como en los enfoques críticos: propuesta epistemológica, existencial, ética, arte de narrar y papel de la literatura.

6 El problema de la verdad y su manipulación ocupa una posición central en el mundo mariesco. Su narrativa se inserta, como lo subraya Gonzalo Navajas, dentro de una concepción contemporánea del saber, de una fragmentación epistemológica que no desemboca sin embargo en un total relativismo y unas de cuyas facetas más originales es la concepción de la mentira como parte de la verdad. La desconfianza hacia las verdades aparentes, tan propio de la edad postmoderna, convierte la escritura en exploración de un territorio situado más allá de la doxa (Alexis Grohman) y determina una sintaxis narrativa específica que José María Pozuelo Yvancos relaciona con lo que la retórica llamaba «estados conjeturales» - el desarrollo del discurso a partir de varias hipotesis -, uno de los rasgos más singulares de la prosa del escritor. La propuesta cognitiva incluye la visión como instrumento hermenéutico que, asociado al verbo que la interpreta, da acceso a una comprensión intuitiva de lo sensible que conforma el pensamiento literario y acaba constituyendo una modalidad autobiográfica oblicua (Luis Martín-Estudillo, Elide Pittarello). Por su parte, Rebeca Martín explora el conocimiento de sí mismo por el procedimiento asociativo que hace emerger obsesiones y horrores que no proceden del exterior.

7 Los límites del conocimiento se hacen patentes en la imposibilidad de conocer al otro y de saber de qué sería capaz en situaciones extremas así como en el efecto destructor del tiempo que arrasa el pasado, amenaza la identidad del yo, la memoria individual y colectiva. De ahí la pregnancia de la muerte, particularmente en el tercer volumen, «una poética del tiempo como ejercicio de restitución de la nada o de lo que fue» y la práctica de la narración como postura a la vez estética y existencial, al ser la «única vía de comunicación de los vivos y los muertos (J. M. Pozuelo Yvancos).

8 Varias contribuciones recalcan la trascendencia ética de la trilogía, la novela actual de mayor vigencia y atrevimiento incluso político para Sebastián Faber. La reflexión sobre la violencia y la inserción de Tu rostro mañana en el debate sobre la memoria histórica reaparecen en las contribuciones de Ilse Logie, David K. Herzberger, Sebastián Faber, Isabel Cuñado y Carlos Javier García. La palabra no es inofensiva: «No debería uno contar nunca nada» reza el íncipit de Fiebre y lanza. Relatando se denuncia, se traiciona, se envenena, se transforma a los individuos en una relación recíproca entre vida e historias (C. J. García, D. K. Herzberger). Ambivalentes son, sin embargo, los efectos de 
la narración que por otra parte define, construye al individuo y contribuye a fijar paradójicamente la memoria colectiva: si bien no puede aspirar a representar fielmente el pasado, frente a los relatos factuales siempre provisionales ofrece la ventaja de ser definitiva y por ello de conservar mejor lo que representa. Como lo expone el narrador de Veneno y sueño y adiós citado por S. Faber: «Es como si el último y más eficaz reducto de la memoria fuera lo que la niega, la ficción, obligada a tergiversar los hechos y a distorsionar esa memoria a la vez que la preserva». De ahí una responsabilidad ética de la literatura que, además de combatir el olvido o la indiferencia colectiva (G. Navajas) transmite referentes éticos encarnados en este caso por el padre del narrador, Juan Deza, y su mentor, Peter Wheeler que mueren al final del tercer volumen: el pasado es época de valores ejemplares, frente a un presente vacío de principios (I. Cuñado). Lo cual lleva a S. Faber a comprobar que Javier Marías no asume del todo la autonomía del texto de ficción que sin embargo proclama.

9 La peculiaridad del arte de narrar es otra vertiente de la narrativa de Javier Marías presente en casi todas las contribuciones. Tu rostro mañana pertenece a la categoría de las «novelas pensamentales» que forjó Gonzalo Sobejano. Ese «pensar por novelas» (J. Gracia) determina la «estructura en progreso» de la obra que J. M. Pozuelo Yvancos compara con el caudal de un río que crece a partir de una pregunta inicial (cómo determinados seres pudieron desencadenar, en circunstancias dadas, comportamientos abyectos), en un proceso de indagación constante, y determina también una composición dialógico-conversacional (ídem). Otra peculiaridad de ese «pensar literario» es el uso de numerosísimas citas y referencias literarias que, lejos de ser digresiones, hacen progresar el relato (Antonio Iriarte). Es otro rasgo constitutivo de esta modalidad literaria del pensar, el ritmo, la cadencia tan consustancial a la prosa de Marías, que se pierde su seducción cuando no se respeta en ciertas traducciones (Maarten Steenmeijer). En fin, el último aporte de la propuesta narrativa de Tu rostro mañana subrayado en este libro es el modelo cultural inclusivo que adopta haciendo dialogar cultura canónica y cultura popular (artes visuales, música, esquemas narrativos de géneros populares, etc.), en una interacción de estéticas contrapuestas (G. Navajas).

10 El primer mérito del volumen es la elección del autor - una de las figuras más relevantes de la narrativa española y europea actuales - y de la obra - una novela en la que culmina de momento la trayectoria del novelista. Su interés reside aún en la cualidad de los contribuidores, especialistas destacados de la novela española contemporánea de distintas universidades europeas y estadounidenses, y en la complementariedad de los enfoques. Allí donde uno diría que ya no puede haber nada. Tu rostro mañana de Javier Marías constituye una eficaz introducción a la obra del novelista - a la vez que un valioso instrumento de trabajo para los especialistas. El lector descubre conjuntamente lo que probablemente sea la obra maestra de Javier Marías y claves para una cabal comprensión de sus precedentes novelas. 